
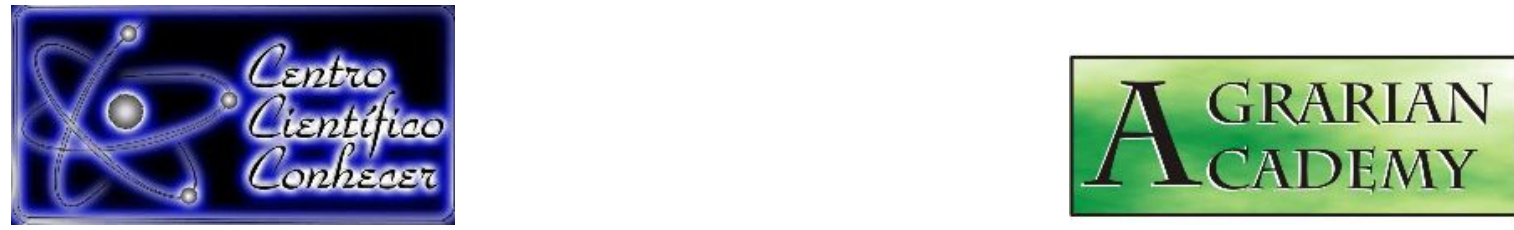

\title{
COMPORTAMENTO DE CULTIVARES DE TOMATE CEREJA SELECIONADAS PARA AMAZÔNIA CENTRAL
}

\author{
Mylena Rego Panza ; Danilo Fernandes Silva Filho ${ }^{2}$; Ariel Dotto Blind ${ }^{3}$; Roneres \\ Deniz Barbosa ${ }^{4}$; Caroline de Moura Vasconcelos ${ }^{1}$
}

1-Graduando(a) em Agronomia, Universidade Federal do Amazonas (UFAM), Programa de Iniciação Cientifica, Instituto Nacional de Pesquisas da Amazônia (INPA), Manaus-AM, Brasil.

2-Pesquisador Dr. Instituto Nacional de Pesquisas da Amazônia (INPA) Professor de

Pós-Graduação em Agricultura no Tropico Úmido (ATU), Manaus-AM, Brasil.

3-Técnico Dr. Estação Experimental de Hortaliças, Instituto Nacional de Pesquisas

da Amazônia (INPA) Manaus-AM, Brasil. ariel.blind@inpa.gov.br

4-Mestrando(a) em Agricultura no Tropico Úmido (ATU), Instituto Nacional de

Pesquisas da Amazônia (INPA), Manaus-AM, Brasil.

Recebido em: 02/06/2019 - Aprovado em: 15/06/2019 - Publicado em: 22/07/2019

DOI: 10.18677/Agrarian_Academy_2019a10

\begin{abstract}
RESUMO
A utilização de cultivares adaptadas as condições edafoclimaticas de uma macro ou microrregião, podem proporcionar desempenho agronômico igual ou superior a variedades tradicionais. Ensaios de competição de cultivares tornan-se indispensáveis para que novos materiais sejam descobertos e para apresentação de coeficientes produtivos. Neste sentido, o presente trabalho evidência o desempenho agronômico de novas cultivares de tomate cereja selecionados para Amazônia central. $O$ delineamento experimental adotado foi em blocos cazualidados a campo em Latossolo amarelo de textura arenosa, com 5 cultivares, sendo uma, indicada para clima tropical. Os parâmetros avaliados durante 6 colheitas foram, número de frutos, massa dos frutos, comprimento x largura dos frutos, sólidos solúveis totais, $\mathrm{pH}$ da polpa, determinação do formato do fruto e do comportamento de variáveis produtivas por analise de regressão. As novas cultivares Yoshin e Careiro, apresentaram produção estatisticamente equivalente a cultivar comercial Carolina ${ }^{\circledR}$ para número e massa de frutos, podendo render até 43 frutos/planta por colheita e acumular acima de $2.800 \mathrm{~g} /$ planta. Estas novas cultivares apresentam peculiaridades de formato dos frutos podendo ser oval, redondo ou achatado além de manifestarem ${ }^{\circ}$ Brix e $\mathrm{pH}$ da polpa inferior a cultivar comercial, sendo frutos pouco doces e são relativamente ácidos. No geral verificou-se comportamento de natureza quadrático pela análise de regressão entre as colheitas, em que o número de frutos produzidos por planta, atinge a máxima, somente na quinta colheita, inversamente ao peso de frutos que a máxima foi identificada na primeira e segunda colheita. $O$ 'Brix e o $\mathrm{pH}$ da polpa manteram-se estáveis durante as colheitas.
\end{abstract}

PALAVRAS-CHAVE: Linhagem Yoshimatsu, plasticidade genotípica, Solanum licopersicum. 


\title{
BEHAVIOR OF CULTIVARS CHERRY TOMATO SELECTED FOR CENTRAL AMAZONIA
}

\begin{abstract}
The use of cultivars adapted to the edapho-climatic conditions of a macro or microregion can provide agronomic performance equal to or greater than traditional varieties. Tests of competition of cultivars become indispensable for new materials to be discovered and for the presentation of productive coefficients. In this sense, the present work evidences the agronomic performance of new cultivars of cherry tomato selected for central Amazonia. The experimental design was in blocks cazualidados in the field in yellow Latosol of sandy texture, with 5 cultivars, being one, indicated for tropical climate. The parameters evaluated during 6 harvests were fruit number, fruit mass, length $x$ width of fruits, total soluble solids, pulp $\mathrm{pH}$, determination of fruit shape and behavior of productive variables by regression analysis. The new Yoshin and Careiro cultivars presented a statistically equivalent production of Carolina $\AA$ commercial variety for number and mass of fruits, yielding up to 43 fruits / plant per harvest and accumulating above $2,800 \mathrm{~g} /$ plant. These new cultivars have peculiarities of fruit shape that can be oval, round or flattened in addition to demonstrating ${ }^{\circ}$ Brix and $\mathrm{pH}$ of the lower pulp to the commercial cultivar, being fruits little sweet and are relatively acid. In general, a behavior of a quadratic nature was verified by the regression analysis between the harvests, where the number of fruits produced per plant reaches the maximum, only in the fifth harvest, inversely to the weight of fruits that the maximum was identified in the first and second harvest. The ${ }^{\circ}$ Brix and the $\mathrm{pH}$ of the pulp remained stable during the harvests.
\end{abstract}

KEYWORDS: Lineage Yoshimatsu, genotypic plasticity, Solanum lycopersicum,

\section{INTRODUÇÃO}

O tomate (Lycopersicum esculentum Mill) apresenta alta importância no agronegócio mundial é considerada como a hortaliça fruto de maior impacto econômico na olericultura brasileira em virtude da demanda entre consumidores e o pacote tecnológico empregada durante sua produção (AMBROSANO et al., 2015; SILVA et al., 2017).

Os frutos são consumidos in natura em saladas ou em pratos diversos, pois é rico em vitaminas, sais minerais e possui propriedades nutraceuticas ajudando a evitar edemas na próstata (SOARES ; FARIAS 2012). A produção de tomate cereja é mais expressiva na região sul e sudeste do Brasil (IBGE 2019), tanto pela popularização entre os consumidores e também pelas condições edafoclimaticas serem favoráveis a produção (NEGRISOLI et al., 2015; YURI et al., 2016). Para estas regiões existem dezenas de variedades, híbridos e cultivares que podem apresentar ampla variação de cores, formatos (FERNANDES et al., 2007; PRECZENHAK et al., 2014) algumas com características peculiares relacionadas ao alto teor de ${ }^{\circ}$ Brix e $\mathrm{o} \mathrm{pH}$ da polpa, e ainda podem apresentar menor acidez (VARGAS et al., 2015; HOLCMAN et al., 2015).

O cultivo de tomate de cereja no Brasil, principalmente em regiões de baixa altitude, ainda experimenta desafios fitossanitários e fisiológicos que podem amargar sérios prejuízos aos olericultores desta hortaliça (PENA et al., 2010; SILVA et al., 2011). A grande maioria das cultivares, variedades e híbridos de tomate disponível, não possuem resistência e/ou tolerância a fito patógenos e não são recomendadas 
as condições de alta temperatura e altitudes inferiores a $400 \mathrm{~m}$ (PEREIRA et al., 2012; MARTINS et al., 2013; SILVA et al., 2017). Não obstante, empresas do ramo não lançam cultivares específicas para uma determinada região, o que torna o investimento muito arriscado, visto que a escolha do cultivar pode ser determinante para o agricultor em função da plasticidade genotípica sob condições ambientais contrastantes. Programas de melhoramento de variedades e cultivares na região norte do Brasil são escassos no entanto em meados de 2013, novas cultivares de tomate cereja foram selecionadas no Instituto Nacional de Pesquisas da Amazônia INPA (MARQUES et al., 2018).

A tecnificação do cultivo de tomate também é bastante expressiva no Brasil e aproveita de ambientes munidos com climatizadores, telas termorefletoras, filmes plásticos uso de substrato e fertirrigações controladas (PEIL et al., 2014; NADAl et al., 2015; SILVA et al., 2017). Estas tecnologias podem originar produtividades que chegam a $200 \%$ a mais do que o convencional proporcionando múltiplas colheitas e oferta o ano todo (COSTA et al., 2015; LÚCIO et al., 2015), porém é indispensável planejar e calcular custos $x$ benefícios principalmente de insumos no local onde pretende-se explorar a cultura.

As condições edafoclimaticas da Amazônia central são peculiares e estão sujeitas a duas épocas distintas, a estação chuvosa que inicia em meados de dezembro e culmina com a estação seca, que inicia em meados de junho, porem na Amazônia central mesmo em período de estiagem ocorrem chuvas temporãs. Nessa região as temperaturas oscilam em média de $22{ }^{\circ} \mathrm{C}$ a $38^{\circ} \mathrm{C}$, com média geral de $27,5^{\circ} \mathrm{C}$, (INMET, 2017) o que é desfavorável a tomaticultura, sendo que para a maioria das cultivares existentes o ideal seria em torno de $20 \pm 5{ }^{\circ} \mathrm{C}$, principalmente no momento de floração que determina o pegamento de frutos (PEREIRA et al., 2012; HOLCMAN et al., 2015). Os solos da região são geralmente Latossolos ou Argisolos que são favoráveis a cultura, porem também possui Neosolos - solos de várzea com fertilidade natural elevada, e os Latossolos de textura arenosa que são considerados menos favoráveis ao cultivo de tomate (FILGUEIRA, 2013; ARAUJO et al., 2017) no entanto passiveis de melhorias das composições físico químicas.

No estado do Amazonas, na região metropolitana de Manaus a procura e o alto preço do tomate cereja tem impulsionado novos investimentos no setor primário, e tem levado a procura por novos materiais genéticos tolerantes e que tenham produção satisfatória independente da época do ano de cultivo (SILVA et al., 2017; MARQUES et al., 2018). Neste sentido o presente estudo buscou evidenciar o desempenho de cultivares de tomate cereja selecionadas para o plantio a campo em condição quente e úmida da Amazônia central.

\section{MATERIAL E MÉTODOS}

Os dois ensaios experimentais ocorreram em solo Latossolo Amarelo distrófico de textura arenosa conforme classificação de solos da EMBRAPA (2013). No local escolhido, realiza-se cultivo rotacionado de olericolas na Estação Experimental de Hortaliças - INPA situada em Manaus-AM nas coordenadas de latitude 2'59'S, longitude 60 01'W em altitude de $60 \mathrm{~m}$. O clima da região é caracterizado como tipo Afi - equatorial quente e úmido, conforme classificação de Koopen - Geiser (ALVARES et al., 2013) e apresenta média de precipitação de $2300 \mathrm{~mm}$ anual. A análise do solo onde foi implantado os experimentos apresentou as seguintes composições químicas: $\mathrm{pH}\left(\mathrm{H}_{2} 0\right)$ 5,8; matéria orgânica 10,5\%; P 38 mg $\mathrm{kg}^{-1}$; K $12 \mathrm{mg} \mathrm{kg}^{-1}$; Ca 2,10 $\mathrm{cmol} \mathrm{kg}^{-1}$; Mg 0,70 $\mathrm{cmol} \mathrm{kg}^{-1}$; acidez potencial 2,40 $\mathrm{cmol}$ 
$\mathrm{kg}_{-1}$; capacidade de troca de cátions $8,30 \mathrm{cmol} \mathrm{kg}^{-1}$. A mesma análise de solo da área, serviu de base para fertilização das subáreas, para cada época de implantação das cultivares entre os anos de 2016 em período de estiagem e 2017 em período chuvoso.

As cultivares Nyshoi, Shony e Yoshin testadas tanto na estação seca quanto na estação chuvosa, foram selecionadas entre os anos de 2013 a 2017 pelo método genealógico. São oriundas da linhagem de tomate de mesa Yoshimatsu de 1984 que foi desenvolvida para região e possui resistência horizontal a Ralstonia solanacearum R1 e R2 e tolerância a altas temperaturas (PENA et al., 2010; MARTINS et al., 2013). Estas novas cultivares segregantes da variedade Yoshimatsu também exibem comumente crescimento indeterminado e foram escolhidas por características fenotípicas típicas de tomate cereja as quais foram batizadas com nomes derivados da variedade mãe.

A cultivar de tomate cereja Careiro foi selecionada entre olericultores do município de Careiro da Várzea - AM e não possui origem genética comprovada, porém é popularmente utilizada na região a vários anos. Carolina ${ }^{\circledR}$ é cultivar comercial tradicionalmente plantada entre olericultores, por apresentar boa produção na região e possuir indicação para clima tropical.

As cultivares foram semeadas em bandeja de poliestireno expandido de 128 células utilizando substrato comercial Plantmax Hortaliças $\mathrm{HT}^{\circledR}$ e mantidas em viveiro protegido até atingirem porte de $15 \mathrm{~cm}$ e 3 folhas definitivas conforme sugestões de Filgueira (2013), Silva et al. (2017).

Nos dois experimentos a fertilização foi realizada nas leiras de cultivo espaçadas a 1,2 x 1,2 m e baseou-se na sugestão de Filgueira (2013) para tomate. 20 dias antecedendo o transplante, foi aplicado e incorporado por metro linear de cultivo: $200 \mathrm{~g}$ do formulado NPK 4-14-8 com $100 \mathrm{~g}$ calcário dolomítico PRNT $86 \%$ e $2 \mathrm{~kg}$ de composto de galinha poedeira. 30 dias após o transplante foi aplicado uma fertilização de cobertura com $20 \mathrm{~g}$ de N, Ureia e $20 \mathrm{~g}$ de K, Cloreto de Potássio para cada planta. A desbrota ocorreu somente até a formação do primeiro cacho de frutos nas plantas, e o tutoramento das plantas foi por meio de fitilho sustentado em arame galvanizado preso em mourões, conforme sugestões de Silva et al. (2017). Nas duas épocas de cultivo e avaliação, a fertilização, o preparo de solo a formação de mudas, transplante e tratos culturais foram semelhantes, exceto a irrigação efetuada na estação seca que foi por meio de fita gotejadora e no período chuvoso não foi preciso de aparatos de irrigação.

A colheita dos frutos maduros foi realizada em intervalos de 5 em 5 dias e as características avaliadas durante 6 colheitas em cada época experimental foram; número médio de frutos produzidos $\left(\mathrm{n}^{\circ}\right)$, massa média dos frutos $(\mathrm{g})$, comprimento médio dos frutos $(\mathrm{mm})$, largura média $(\mathrm{mm})$, sólidos solúveis totais ( $\left.{ }^{\circ} \mathrm{Brix}\right)$ e $\mathrm{pH}$ da polpa (\%). Para determinação do ${ }^{\circ}$ Brix e pH foram amostrados em cada coleta de cada época avaliada, 5 frutos, retirados ao acaso e posteriormente determinados valores conforme sugestões de Guilherme et al. (2014) por meio de refratômetro digital AOAC - 1977 e pHmetro - Quimis 510. Foi realizado a classificação do formato dos tomates pela relação comprimento $(C) \times$ largura $(L)$ dos frutos em que $o$ formato (A) oval: $\mathrm{C}>\mathrm{L}$; formato (B) redondo: $\mathrm{C}=\mathrm{L}^{-1}$ e formato (C); achatado: $\mathrm{C}<\mathrm{L}$ baseado por implicações dos estudos de Fernandes et al. (2007).

Os dados das duas épocas experimentais foram reunidos em números médios e submetidos a análise de variância pelo teste $\mathrm{F}$ - Fischer. As médias foram comparadas pelo teste Duncan por meio de auxilio de software Assistat v. $7.7 \AA$ 
(SILVA et al., 2016). Também foi realizado análise de regressão para identificar o comportamento de algumas variáveis produtivas utilizando pacote Excel - 2013®.

\section{RESULTADOS E DISCUSSÃO}

Os resultados obtidos permitem indicar novas cultivares de tomate cereja aos olericultores da região em função das médias de produção, características fenotípicas e qualitativas avaliadas. Pela Tabela 1, verifica-se que para o número de frutos produzidos entre as cultivares na média de 6 colheitas, Careiro, acumulou o maior valor de frutos com 44,8 unidades não diferindo estatisticamente de Carolina ${ }^{\circledR}$ 43,9 e Yoshin com 43,5 frutos para cada colheita.

TABELA 1: Média das características avaliadas entre as cultivares de tomate cereja cultivados em duas épocas na condição edafoclimatica da Amazônia central. INPA, Manaus-AM, 2019.

\begin{tabular}{|c|c|c|c|c|c|c|}
\hline Cultivares & $\begin{array}{c}N^{\circ} \text { de frutos } \\
\left(n^{\circ}\right)\end{array}$ & $\begin{array}{l}\text { Comp. frutos } \\
(\mathrm{mm})\end{array}$ & $\begin{array}{l}\text { Larg. frutos } \\
(\mathrm{mm})\end{array}$ & $\begin{array}{c}\text { Peso } \\
\text { fruto }(\mathrm{g})\end{array}$ & $\begin{array}{c}\text { Sol. S. T. } \\
\left({ }^{\circ} \text { Brix }\right)\end{array}$ & $\begin{array}{c}\mathrm{pH} \text { polpa } \\
(\%)\end{array}$ \\
\hline Nyshoi & $30,75 \mathrm{~b}$ & $19,41 \mathrm{~b}$ & $21,15 d$ & $8,65 c$ & $5,44 \mathrm{~b}$ & $3,93 \mathrm{~b}$ \\
\hline Shony & $31,45 \mathrm{~b}$ & $28,38 \mathrm{a}$ & $32,69 a$ & $23,4 \mathrm{a}$ & $6,03 a$ & $4,05 \mathrm{a}$ \\
\hline Yoshin & 43,58 a & $22,13 \mathrm{~b}$ & $24,84 \mathrm{c}$ & $10,94 \mathrm{c}$ & $5,86 \mathrm{~b}$ & $4,01 \mathrm{~b}$ \\
\hline Careiro & 44,83 a & $23,99 \mathrm{~b}$ & $27,48 \mathrm{~b}$ & $13,51 b$ & $5,29 \mathrm{~b}$ & $4,16 \mathrm{a}$ \\
\hline Carolina $^{\circledR}$ & $43,95 \mathrm{a}$ & $28,17 \mathrm{a}$ & $21,43 d$ & $8,5 \mathrm{c}$ & $6,19 a$ & $4,39 \mathrm{a}$ \\
\hline CV (\%) & 21,9 & 16,4 & 10,7 & 8,6 & 9,1 & 10,2 \\
\hline \multicolumn{7}{|c|}{ ANAVA (Teste F) } \\
\hline $\begin{array}{c}\text { Estações (Seca) } \\
\text { e (Chuvosa) }\end{array}$ & $1,3456^{\text {ns }}$ & $0,9864^{\mathrm{ns}}$ & $1,1209^{\text {ns }}$ & $0,4560^{\mathrm{ns}}$ & $0,3274^{\mathrm{ns}}$ & $1,1201^{\mathrm{ns}}$ \\
\hline Cultivares & $5,6578^{*}$ & $10,3288^{* *}$ & $8,2180^{* *}$ & $4,5875^{\star}$ & $7,8210^{* *}$ & $2,8969^{*}$ \\
\hline Interação E x C & $1,5455^{\mathrm{ns}}$ & $1,2310^{\mathrm{ns}}$ & $0,9887^{\mathrm{ns}}$ & $0,7634^{\mathrm{ns}}$ & $0,8168^{\mathrm{ns}}$ & $1,1008^{\mathrm{ns}}$ \\
\hline
\end{tabular}

** Significativo a $1 \% \mathrm{e}^{*} 5 \%$ de probabilidade e ns não significativo pelo teste $\mathrm{F}$. Médias seguidas de mesma letra nas colunas não diferem entre si ao nível de 5\% de significância pelo teste Duncan

Neste mesmo sentido de análise, as duas cultivares selecionadas Careiro e Yoshin, acumularam produção satisfatória quando comparadas a cultivar comercial Carolina ${ }^{\circledR}$. Em 6 colheitas efetuadas durante 30 dias estes materiais renderam acima de $2.860 \mathrm{~g} /$ planta, o que é um bom índice produtivo, ainda mais quando se utiliza de coeficientes econômicos de venda para Manaus que está em torno de $R \$ 7,50$ o quilo em feiras livres.

As cultivares Shony e Nyshoi obtiveram menor número de frutos por colheita e não diferiram estatisticamente entre si, no entanto ao comparar o peso médio de cada fruto é possível verificar que a cultivar Shony produz frutos relativamente mais pesados com média de $23,4 \mathrm{~g} /$ fruto sendo superior a todas as demais cultivares. Esta característica está relacionada com a relação comprimento x largura do fruto, pois estatisticamente Shony também apresentou maiores valores para a largura do fruto e foi caracterizado por apresentar formato do tipo C conforme apresenta a figura 1. A cultivar Careiro também apresentou formato tipo $\mathrm{C}$, porém com frutos menores pela relação comprimento $x$ largura, e menos pesados do que a cultivar Shony. Nyshoi e Yoshin estatisticamente possuem formato tipo B, isto é, redondos, e Carolina $^{\circledR}$ apresentou formato do tipo A, ou seja, frutos ovalados, em que o comprimento é superior a largura. Fernandes et al. (2007) e Preczenhak et al. 
(2014) ponderam que novos materiais genéticos de tomate cereja podem apresentar plasticidade tanto produtiva quanto morfológica ao sistema de cultivo, predizendo que a interação do genótipo $x$ ambiente é o fator mais importante a considerar $\mathrm{e}$ deve ser analisado em vários anos agrícolas.

Oval

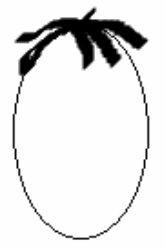

Redondo

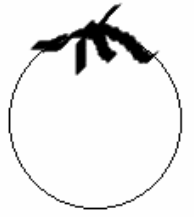

Achatado

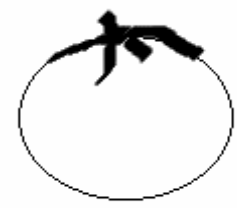

${ }^{1}$ Formato (A): $\mathrm{C}>\mathrm{L} \quad$ Formato (B): $\mathrm{C}=\mathrm{L}^{-1} \quad$ Formato (C): $\mathrm{C}<\mathrm{L}$

${ }^{1}$ Baseado na comparação de médias pelo teste Duncan ao nível de $5 \%$ de significância

FIGURA 1: Determinação do formato de frutos de tomate do grupo cereja, através da relação, comprimento $(C) \times$ largura $(L)$, em duas épocas na condição edafoclimática da Amazônia central. INPA, Manaus-AM, (2019).

Com relação aos Sólidos Solúveis Totais e pH da polpa o maior valor foi identificado para a cultivar Carolina ${ }^{\circledR}$ com média de 6,19 de ${ }^{\circ}$ Brix e pH de 4,39 e ainda assim são valores considerados muito baixos para qualidade de tomate cereja (SILVA et al., 2011; GUILHERME et al., 2014) mesmo que ainda não exista um padrão definido para estas variáveis.

Preczenhak et al. (2014) verificaram em um banco ativo de germoplasma de 64 genótipos de mini tomate em Guarapuava-PR, apenas três genótipos se destacaram quanto ao teor de sólidos solúveis, com 7,37 ${ }^{\circ}$ Brix (IAC1498-63), 7,17 ${ }^{\circ}$ Brix (RVTC-22) e $7,13^{\circ}$ Brix (6878-49) sendo superior ao encontrado no presente estudo para todas cultivares. Os mesmos autores evidenciam que esta característica é passível de aprimoramento genético em seleções futuras e também pode ser melhorada com manejo cultural e nutricional, principalmente durante a frutificação.

Com relação ao comportamento das características relacionadas a produção entre as cultivares, observou-se que no geral a natureza do efeito foi quadrática, ou seja, inicialmente as cultivares produzem poucos frutos e à medida que a planta atinge a maturidade fisiológica o número de frutos aumenta e posteriormente declina com a senescência vegetativa (Figura 2). Esta situação é normal para qualquer cultivar, mesmo que seu crescimento seja indeterminado (SILVA et al., 2011; VARGAS et al., 2015), porem dependendo dos tratos culturais, manejo nutricional e fitossanitário é possível prolongar a vida útil da planta e aumentar o rendimento de colheitas e frutos (PEIL et al., 2014; AMBROSANO et al., 2015). 

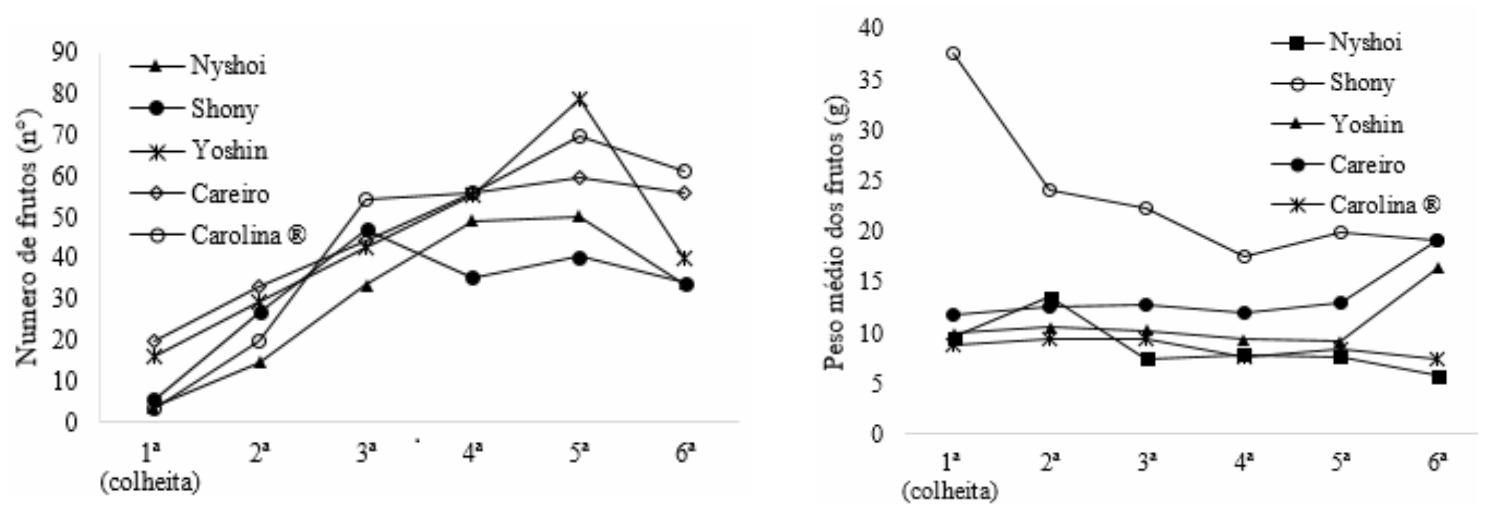

Yoshin $=-3,9464 x^{2}+35,596 x-21,15$

$R^{2}=0,7246$

Nyshoi $=-3,7232 x^{2}+33,891 x-31,4$ $R^{2}=0,9157$

Shony $=-3,5446 x^{2}+29,705 x-18,75$ $R^{2}=0,8574$

Careiro $=-2,0518 x^{2}+22,135 x-1,52$ $R^{2}=0,9865$

Carolina $=-3,692 x^{2}+38,437 x-34,575$ $R^{2}=0,9548$

$$
\begin{gathered}
\text { Yoshin }=0,6061 x^{2}-3,4719 x+13,908 \\
R^{2}=0,6446 \\
\text { Nyshoi }=-0,0868 x^{2}+0,2941 x+8,792 \\
R^{2}=0,5815 \\
\text { Shony }=1,44 x^{2}-13,209 x+47,792 \\
R^{2}=0,9292 \\
\text { Careiro }=0,5221 x^{2}-2,5833 x+14,634 \\
R^{2}=0,7947 \\
\text { Carolina }=-0,0868 x^{2}+0,2941 x+8,792 \\
R^{2}=0,5815
\end{gathered}
$$
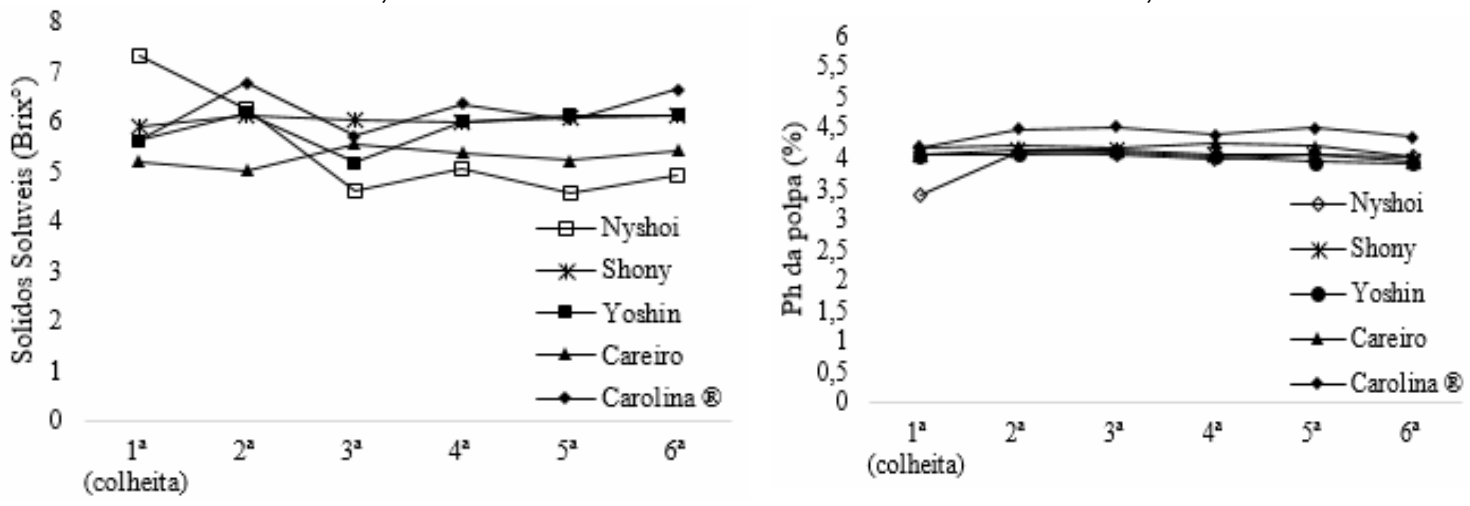

Yoshin $=0,0307 x^{2}-0,1233 x+5,834$ $\mathrm{R}^{2}=0,2311$

Nyshoi $=0,2089 x^{2}-1,9354 x+9,05$ $\mathrm{R}^{2}=0,9183$

Shony $=-0,0048 x^{2}+0,0575 x+5,907$ $R^{2}=0,331$

Careiro $=-0,0146 x^{2}+0,1459 x+5,008$ $\mathrm{R}^{2}=0,2323$

Carolina $=0,0059 x^{2}+0,0627 x+5,881$ $R^{2}=0,1645$

Yoshin $=-0,0121 x^{2}+0,053 x+4,012$ $\mathrm{R}^{2}=0,9103$

Nyshoi $=-0,0589 x^{2}+0,4954 x+3,09$ $\mathrm{R}^{2}=0,6989$

Shony $=-0,0155 x^{2}+0,0799 x+4,011$ $\mathrm{R}^{2}=0,9019$

Careiro $=-0,0175 x^{2}+0,1019 x+4,072$ $R^{2}=0,6696$

Carolina $=-0,0352 x^{2}+0,2657 x+3,997$ $R^{2}=0,6724$

FIGURA 2. Ajustamento da equação de regressão e coeficientes de determinação para produtividade e características qualitativas entre cultivares de tomate cereja cultivados em duas épocas na condição edafoclimatica da Amazônia central. INPA, Manaus-AM, 2019.

Com exceção da cultivar Shony o peso de frutos ao longo das colheitas manteve-se relativamente estável, e esta característica é importante sob ponto de vista comercial, pois são cultivares que apresentam pouca ou nenhuma variação para esta característica independente do estádio vegetativo (Figura 2). Vargas et al. 
(2015) e Silva et al. (2017) relatam que cultivares instáveis, geralmente produzem frutos maiores no início de produção, principalmente na primeira e segunda colheita por terem mais foto assimilados disponível e também porque a planta possui melhor vigor desde a formação de mudas. No entanto, comercialmente cultivares que produzem frutos com mesmo calibre e qualidades pouco variáveis do início ao fim de produção podem ser mais interessantes na escolha do cultivar independente da região de cultivo (ORTIZ ; IZQUIERDO 1994; YURI et al., 2016).

A cultivar Nyshoi apresentou na primeira colheita, ${ }^{\circ}$ Brix acima de 7 , bem superior as demais, porem na sexta colheita $0^{\circ}$ Brix diminuiu para próximo de 5 , denotando que possivelmente 0 fator nutricional $x$ vigor vegetativo esteja influenciando diretamente esta característica. Curiosamente esta mesma cultivar produziu frutos relativamente mais ácidos com pH abaixo de 4 na primeira colheita e posteriormente na segunda colheita os frutos apresentaram-se estáveis com $\mathrm{pH}$ acima de 4 conforme apresenta a equação de regressão na Figura 2.

Costa et al. (2015) e Araujo et al. (2017) relatam que a condição fisiológica e nutricional principalmente em relação aos teores de nitrogênio e potássio sejam determinantes para que a planta em fase de frutificação revele maior valor de sólidos solúveis totais e também produza frutos menos ácidos. Isto pode ser muito relevante para qualidade dos frutos que o mercado exige, pois indica que seja necessário disponibilizar durante a fase de frutificação, fertilizações equilibradas não só de nitrogênio e potássio mais de outros elementos que atuam sinergicamente.

Neste sentido a produção de tomate cereja na região Amazônica ainda é desafiadora, pois envolve respostas no metabolismo de cultivares referentes as condições ambientais principalmente altas temperaturas, fotoperiodismo, umidade do ar, manejo fitossanitário e nutricional que podem atuar individualmente ou em conjunto com o genótipo.

É possível que estas características qualitativas e quantitativas analisadas neste estudo, possam ser instáveis em outra localidade e condição de cultivo, sendo possível ainda, obter ganhos de adaptação sobre a interação genótipo x ambiente e manifestar melhor desempenho produtivo (SILVA et al., 2011; VARGAS et al., 2015). Testes preliminares são extremamente importantes e decisivos para escolha da cultivar, pois evitam prejuízos aos olericultores e permitem planejar o investimento e retorno econômico adequadamente (AMBROSANO et al., 2015; SILVA et al., 2017).

Embora a produção de tomate cereja na Amazônia central seja inferior a região sul e sudeste o cultivo desta hortaliça pode ser favorecido pelo alto valor agregado dos frutos independente da época de cultivo. Desta forma os resultados obtidos neste trabalho revelam a produção de novas cultivares selecionadas para região que podem manifestar rendimento semelhantes as condições de cultivo deste estudo.

\section{CONCLUSÃO}

Em função de apresentarem maior rendimento acumulado, melhor teor de -Brix, pH da polpa e melhor comportamento entre as colheitas, as cultivares Yoshin, Careiro e Carolina ${ }^{\circledR}$, são indicadas para o cultivo e comercialização em condições de clima quente e úmido, independente da época do ano de plantio.

\section{REFERÊNCIAS}

ALVARES, C. A.; STAPE, J. L.; SENTELHAS, P. C.; GONÇALVES, J. L. M.; SPAROVEK, G. Koppen's climate classification map for Brazil. Meteorologische 
Zeitschrift, v. 22, p. 711-728, 2013. Disponível em: <http://dx.doi.org/10.1127/09412948/2013/0507>. DOI:10.1127/0941-2948/2013/0507.

AMBROSANO, E.; ROSSI, F.; DIAS, F.; TAVARES, S.; AMBROSANO, G. Desempenho do tomate-cereja e milho-verde após cultivo de fabaceas e seu efeito no solo. Cadernos De Agroecologia, v.9 n.4. 2015. Disponível em: http://revistas.aba-agroecologia.org.br/index.php/cad/article/view/16773.

ARAUJO, T. da S.; ALMEIDA, A. S.; ARAÚJO, F. S.; FERREIRA, A. H. C.; PASCOA PINTO, T. da. Produção e qualidade de tomates cereja fertirrigados com água residuária da piscicultura. Revista Verde de Agroecologia e Desenvolvimento Sustentável. V.12, n3, p. 392 - 396, 2017. Disponível em:<http://dx.doi.org/ 10.18378/rvads.v12i3.4775>. DOI:10.18378/rvads.v12i3.4775.

COSTA, E.; SANTO, T. L. E.; SILVA, A. P; SILVA, L. E.; OLIVEIRA, L. C.; BENETT, C. G. S.; BENETT, K. S. S. Ambientes e substratos na formação de mudas e produção de frutos de cultivares de tomate cereja. Horticultura Brasileira, 33: 110118. 2015. Disponível em:<http://dx.doi.org/10.1590/S0102-053620150000100018>. DOI: $10.1590 / S 0102-053620150000100018$.

EMBRAPA. Empresa Brasileira de Pesquisa Agropecuária. Centro Nacional de Pesquisa de Solos. Sistema Brasileiro de Classificação de Solos $2^{\mathbf{a}}$ ed. Rio de Janeiro: Embrapa Solos, 306p. 2013.

FERNANDES, C.; CORÁ, J. E.; BRAZ, L. T. Classificação de tomate-cereja em função do tamanho e peso dos frutos. Horticultura Brasileira, Brasília, v.25, n.2, p. 275 - 278, 2007. Disponível em: http://www.scielo.br/pdf/hb/v25n2/28.pdf

FILGUEIRA, F. A. R. Novo Manual de Olericultura - agrotecnologia moderna na produção e comercialização de hortaliças. v. 3. Editora UFV. Viçosa, MG, p.294295, 2013.

GUILHERME, D. O.; PINHO, L.; CAVALCANTI, T. F. M. COSTA.; CÂNDIDO, A.; ALMEIDA, A. C. Análise sensorial e físico-química de frutos tomate cereja orgânicos Revista Caatinga, Mossoró, v. 27, n. 1, p. 181 - 186, 2014. Disponível em: https://periodicos.ufersa.edu.br/index.php/caatinga/article/view/2683

HOLCMAN, E.; SENTELHAS, P. C.; MELLO, S. D. C. Microclimatic changes caused by different plastic coverings in greenhouses cultivated with cherry tomato in southern Brazil. Revista Brasileira de Meteorologia, v. 30, n. 2, p. 125-133, 2015. Disponível em:<http://dx.doi.org/10.1590/0102-778620140094>. DOI: 10.1590/0102778620140094.

IBGE - Instituto Brasileiro de Geografia e Estatística. 2019. Disponível em $<$ http://ftp.ibge.gov.br/Producao Agrícola: Levantamento Sistemático da Produção Agrícola [mensal] /Fascículo/lspa_201501.pdf>. Acesso em: 06 de maio de 2019 
INMET- Instituto Nacional de Meteorologia. 2017. Disponível em: http://www.inmet.gov.br/portal/index.php?r=clima/amazonia/arquivos.html. Acesso em: 06 maio de 2019.

LÚCIO A. D.; SARI, B. G.; RODRIGUES, M.; BEVILAQUA, L. M.; MODESTO, G. V. H.; COPETTI, D.; FAEL, M. Modelos não-lineares para a estimativa da produção de tomate do tipo cereja. Ciência Rural, Santa Maria, Online,2015, 9p.. Disponível em:<http://dx.doi.org/10.1590/0103-8478cr20150067>. DOI:10.1590/01038478 cr20150067.

MARTINS, L. H. P.; NODA, H; MENDONÇA, M. S. P.; MACHADO, F. M. Tomate Yoshimatsu - uma cultivar adaptada ao trópico úmido brasileiro. In: Noda, $\mathrm{H}$.; Silva Filho, D.F.; Souza, L.A.G. Agricultura familiar no Amazonas: conservação ambientais. 1ed. Manaus: NERUA/Instituto Nacional de Pesquisas da Amazônia, p.15-26. 2013.2 Disponível em: https://www.inpa.gov.br/arquivos/Agricultura_Familiar_Vol_1.pdf.

MARQUES, M. J.; ARISPE TORREZ, A. A.; BLIND, A. D.; FIGUEIREDO, J. N. R.; SILVA FILHO, D. F. Comportamento de cultivares de tomate cereja em substratos alternativos. Enciclopédia Biosfera, v.15 n. 27, p. 62 - 69. 2018. Disponível em:<http://dx.doi.org/10.18677/EnciBio_2018A29>.

10.18677/EnciBio_2018A29.

NADAI, F. B.; MENEZES, J. B. C.; CATÃO, H. C. R. M.; ADIVÍNCULA, T.; COSTA, C. A. Produção de mudas de tomateiro em função de diferentes formas de propagação e substratos. Revista agro@mbiente On-line, v.9, n.3, p. 261-267, 2015. Disponível em:<http://dx.doi.org/10.18227/1982-8470ragro.v9i3.2348>. DOl: 10.18227/19828470ragro.v9i3.2348.

NEGRISOLI, R. M.; CECHINATTO, F. H.; BISSOLO, M. J.; ROSESTOLATO, L. L. R.; SABBAG, O. J. Viabilidade econômica de cultivo de minitomate sweet grape no município de Casa Branca/SP. Enciclopédia Biosfera, v.11, n.21, p,1932-1942, 2015.

<http://www.conhecer.org.br/enciclop/2015b/agrarias/viabilidade\%20economica $\% 20$ no\%20cultivo\%20de\%20minitomate.pdf >.

PENA, M. A. A.; NODA, H.; MACHADO, F. M.; PAIVA, M. S. S. Adaptabilidade e estabilidade de genótipos de tomateiro sob cultivo em solos de terra firme e várzea da Amazônia infestados por Ralstonia solanacearum. Bragantia, v.69, n.1, p.27-37, 2010. Disponível em:<http://dx.doi.org/10.1590/S0006-87052010000100005>. DOI: 10.1590/S0006-87052010000100005.

ORTIZ, R.; IZQUIERDO J. Yield stability differences among tomato genotypes grown in Latin America and the Caribbean. HortScience, v. 29, n. 10, p. $1175-1177$, 1994. Disponível em:<http://dx.doi.org/10.21273/HORTSCI.29.10.1175. DOI: 10.21273/HORTSCI.29.10.1175

PEIL, R. M. N.; ALBUQUERQUE NETO, A. A. R.; ROMBALDI, C. V. Densidade de plantio e genótipos de tomateiro cereja em sistema fechado de cultivo em substrato. 
Horticultura Brasileira, 32: 234-240. 2014. Disponível em: http://dx.doi.org/10.1590/S0102-05362014000200021. DOI: 10.1590/S010205362014000200021

PRECZENHAK, A. P.; RESENDE, J. T. V.; CHAGAS, R. R.; SILVA, P.R.; SCHWARZ, K.; MORALES, R. G. F. Caracterização agronômica de genótipos de minitomate. Horticultura Brasileira, v.32, p. 348-356. 2014. Disponível em:<http://dx.doi.org/10.1590/S0102-05362014000300018>. DOI: 10.1590/S010205362014000300018.

PEREIRA, M. A. B.; MÁRCIO DE AZEVEDO, S.; ARAÚJO DE FREITAS, G.; SANTOS G. R.; NASCIMENTO, I. R. Adaptabilidade e estabilidade produtiva de genótipos de tomateiro em condições de temperatura elevada. Revista Ciência Agronômica, v. $43, \quad$ n. 2, p. 330-337. 2012. Disponível em: http://ccarevista.ufc.br/seer/index.php/ccarevista/article/view/1423

SOARES, J. A. P.; FARIAS, L. M. Efeito do licopeno do tomate na prevenção do câncer de próstata. Novafapi, Teresina, v. 5, n. 2, p. 50-54, 2012. Disponível em: https://revistainterdisciplinar.uninovafapi.edu.br/revistainterdisciplinar/v5n2/rev/rev2v $5 \mathrm{n} 2 . p d f$

SILVA, F. de A. S.; AZEVEDO, C. A. V. de. The Assistat Software Version 7,7 and its use in the analysis of experimental data. African Journal of Agricultural Research, v.11, n.39, p. 3733 - 3740, $2016 . \quad$ Disponível em: <http://dx.doi.org/10.5897/AJAR2016-11522 >. DOI:10.5897/AJAR2016-11522.

SILVA, A. C.; COSTA, C. A.; SAMPAIO, R. A.; MARTINS, E. R. Avaliação de linhagens de tomate cereja tolerantes ao calor sob sistema orgânico de produção. Revista Caatinga, Mossoró, v. 24, n. 3, p. 33-40, 2011. Disponível em: https://periodicos.ufersa.edu.br/index.php/caatinga/article/view/2274

SILVA, P. A. da, RABELO, J. da S.; GUIMARÃES, M. de A.; SILVA, J. C. do V.; OLIVEIRA, L. S. C. Sistemas de condução na produção comercial de tomate "cereja" Nativa, Sinop, v.5, n.5, p. $316 \quad$ - 319, 2017. Disponível em:http://dx.doi.org/10.5935/2318-7670.v05n05a03>. DOI: 10.5935/23187670.v05n05a03.

VARGAS, T. O.; ALVES, E. P.; ABBOUD, A. C. S.; LEAL, M. A. A.; CARMO, M. G. F. Diversidade genética em acessos de tomateiro heirloom. Horticultura Brasileira, v.33, p.174 - 180. 2015. Disponível em:<http://dx.doi.org/10.1590/S0102053620150000200007>. DOI: 10.1590/S0102-053620150000200007.

YURI, J. E.; COSTA, N. D.; COÊLHO DE LIMA, M. A.; RESENDE, G. M.; FERREIRA, T. D.; SILVA, M. C. Mini tomato cultivars for the sub-mid São Francisco valley, Brazil Revista Caatinga, Mossoró, v. 29, n. 4, p. 1015 - 1020, 2016. Disponível em:<http://dx.doi.org/10.1590/1983-21252016v29n427rc>. DOI: 10.1590/1983-21252016v29n427rc. 